Haase

Geistiges Eigentum im Steuerrecht 



\section{Geistiges Eigentum}

Nationales und Internationales Steuerrecht der immateriellen Wirtschaftsgüter

herausgegeben von

Dr. Florian Haase, M.I. Tax

Rechtsanwalt/Fachanwalt

für Steuerrecht

Head of German Tax Group,

Partner,

DLA Piper, Hamburg

2012

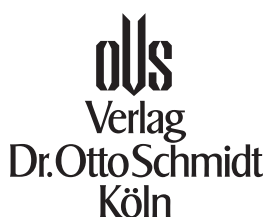

Köln 



\section{Autoren}

Dr. Katrin Dorn

Steuerberaterin

Associate, DLA Piper, Hamburg

Julia Gehri, MBA

Steuerberaterin

Senior Manager, KPMG AG, Hamburg

\section{Dr. Markus Greinert}

Steuerberater

Partner, Flick Gocke Schaumburg,

München

Dr. Florian Haase, M.I. Tax

Rechtsanwalt/Fachanwalt für

Steuerrecht

Head of German Tax Group, Partner,

DLA Piper, Hamburg

\section{Ronald Hager}

Rechtsanwalt/Wirtschaftsprüfer

Associate Partner, Rödl \& Partner,

München

Dr. Christian Heinze, LL.M.

Wissenschaftlicher Referent

Max-Planck-Institut für Ausländisches

und Internationales Privatrecht,

Hamburg

Dipl.-Finanzwirt Matthias Hofacker,

M.I. Tax

Rechtsanwalt/Steuerberater

Senior Manager, KPMG AG, Bremen

Birgit Jürgensmann

Rechtsanwältin/Fachanwältin für

Steuerrecht/Steuerberaterin

Partnerin, Deloitte \& Touche GmbH, Hamburg
Bastian Ruge, LLM.

Rechtsanwalt

Associate, Watson, Farley \& Williams, Hamburg

Daniela Steierberg, LLM.

Steuerberaterin

Senior Associate, DLA Piper, Hamburg

Dr. Katja Weigert, LL.M. oec.

Steuerberaterin

Associate, Flick Gocke Schaumburg, München 


\section{Bibliografische Information}

der Deutschen Nationalbibliothek

Die Deutsche Nationalbibliothek verzeichnet diese Publikation in der Deutschen Nationalbibliografie; detaillierte bibliografische Daten sind im Internet über http://dnb.d-nb.de abrufbar.

Verlag Dr. Otto Schmidt KG

Gustav-Heinemann-Ufer 58, 50968 Köln

Tel. 02 21/9 37 38-01, Fax 02 21/9 37 38-943

info@otto-schmidt.de

www.otto-schmidt.de

ISBN 978-3-504-26025-5

C2012 by Verlag Dr. Otto Schmidt KG, Köln

Das Werk einschließlich aller seiner Teile ist urheberrechtlich geschützt. Jede Verwertung, die nicht ausdrücklich vom Urheberrechtsgesetz zugelassen ist, bedarf der vorherigen Zustimmung des Verlages. Das gilt insbesondere für Vervielfältigungen, Bearbeitungen, Übersetzungen, Mikroverfilmungen und die Einspeicherung und Verarbeitung in elektronischen Systemen.

Das verwendete Papier ist aus chlorfrei gebleichten Rohstoffen hergestellt, holz- und säurefrei, alterungsbeständig und umweltfreundlich.

Einbandgestaltung: Jan P. Lichtenford, Mettmann Satz: Schäper, Bonn Druck und Verarbeitung: CPI - Clausen \& Bosse, Leck Printed in Germany 